\title{
Militantismo sindical en Chile. Subjetivación, estrategia y socialización en trayectorias individuales
}

\author{
Chilean Union Activism. \\ Subjectivation, strategy and socialization in individual \\ careers
}

Francisca Gutiérrez Crocco ${ }^{1}$

Resumen

El artículo presenta una discusión teórica sobre la manera de concebir las trayectorias de los dirigentes sindicales. La sociología ha ayudado a oponer tres figuras: el militante de estructura, el militante profesional y el militante iluminado. Cada una se caracteriza por intentar explicar el comportamiento de los dirigentes según una sola lógica: la primera, según la lógica de socialización; la segunda, según la lógica estratégica; la tercera, según la lógica de subjetivación. Siguiendo la línea de varios autores contemporáneos, se plantea la necesidad de integrar estos tres modelos. Para ello se propone un modelo centrado en la noción de acontecimiento como detonador de un proceso de subjetivación, y la noción de espacio como conjunto de posibles combinaciones de estrategias y determinaciones sociales.

Palabras clave: Sindicalismo, Militantismo, Teoría social, Subjetivación, Sujeto, Trayectorias, Relatos de vida.

1 Doctorante École des Hautes Études en Sciences Sociales (EHESS), París, Francia; fgcrocco@gmail.com 
Abstract

This paper presents a theoretical discussion focused on how to conceive the careers of union activists. Sociology has helped to build three antagonist figures of activist: the structure activist, the professional activist and the illuminated activist. Each one attempts to explain activist behavior by an exclusive logic: the first, by the socialization logic; the second, by the strategic logic; the third, by the subjectivation logic. Following the line of several contemporary authors, the integration of these three models is proposed by using an approach focused on the notion of event as a trigger of a subjectivation process, and on the notion of space as a set of possible combinations of strategies and social determinations.

Key words: Unionism, Activism, Social theory, Subjectivity, Subject, Careers, Life history.

\section{Introducción}

Desde la década del noventa en adelante el sindicalismo chileno ha perdido su visibilidad como objeto de estudio. El entusiasmo que suscitó al alero del socialismo en los años setenta y del proceso de democratización que siguió a la dictadura militar en los años ochenta, parece haberse agotado.

En reacción al desinterés predominante diseñamos una investigación que se propone entender los procesos que vive el sindicalismo en nuestro país desde el estudio de las trayectorias de sus militantes. Por un lado, se trata de conocer, a través de la recolección de relatos de vida, los procesos que llevan a un trabajador a convertirse en dirigente sindical y cómo ese nuevo compromiso evoluciona en el tiempo. Por el otro, se trata de analizar qué nos dicen esas trayectorias acerca de la manera en que el sindicalismo se inserta en el contexto social, político y económico actual.

El enfoque posee dos ventajas. En primer lugar, al preguntarse por las trayectorias de vida, interroga una dimensión dada a menudo por hecho: 
el compromiso del individuo con una causa colectiva. El militantismo no es en absoluto un hecho evidente. Desde un punto de vista estrictamente racional, existe una estrategia mucho más rentable que el compromiso militante, la posición del free-rider o pasajero clandestino (Olson, 1978), es decir, quien se beneficia de los resultados de una acción colectiva sin involucrarse en ella. Más improbable parece el militantismo sindical en el actual contexto chileno. Resulta difícil entender por qué, en un periodo de desindicalización, donde predomina un marco institucional antisindical, y donde el discurso dominante tiende a valorar la responsabilidad individual por sobre la responsabilidad colectiva, los trabajadores aún dedican buena parte de su tiempo a este tipo de actividad.

La segunda ventaja del enfoque consiste en la introducción de una mirada longitudinal. Centrarse en las trayectorias de quienes se transforman en dirigentes sindicales permite introducir la dimensión del tiempo. Primero, poniendo sobre la mesa los cambios, avances, quiebres y retrocesos que va sufriendo el compromiso militante a lo largo de la vida de los individuos. Segundo, abriendo la posibilidad de entender las diferencias que separan a la generación de dirigentes comprometidos antes o durante la dictadura de la generación que comienza a participar a partir de la transición. Los enfoques sociológicos tradicionales tienden a estudiar el sindicalismo como una variable sincrónica o, en el mejor de los casos, como un fenómeno cuyos únicos cambios relevantes se miden en la larga duración. El nuestro tiene a su favor el atender la historia de mediana y corta duración.

Con el trabajo de terreno y la revisión de la literatura especializada nos dimos cuenta que uno de los desafíos mayores consiste en superar las definiciones de militantismo dominantes pues resultan inadecuadas para dar cuenta de la realidad. El problema está en que cada modelo pretende explicar la conducta militante desde una sola lógica: como producto de las decisiones racionales de los individuos, como producto de un proceso de subjetivación que le permite al individuo elevarse por sobre su realidad o como un producto de las determinaciones del medio. Si bien existe cierto consenso acerca de la necesidad de integrar dichas miradas, en la práctica los trabajos de investigación tienden a favorecer una en desmedro de la otra. 
Con la idea de avanzar en este sentido, proponemos utilizar dos nuevos conceptos que combinan las diferentes lógicas en juego, a saber el concepto de acontecimiento, prestado de la filosofía política, y el de espacio, resultado de la unión de ciertos planteamientos de la sociología. Se trata de entender la trayectoria del militante sindical como una serie de acontecimientos encadenados que van abriendo espacios relativamente nuevos donde se actualizan normas particulares y donde se potencian ciertas estrategias que le dan una forma específica al compromiso sindical, es decir, a ese triángulo que se establece cuando un trabajador asume una responsabilidad sindical, entre el nuevo militante, un grupo de trabajadores de referencia y una contraparte o figura del capital.

Dedicaremos este artículo a la explicitación de esta propuesta y los argumentos que nos llevan a ella. Si bien se trata mayoritariamente de un ejercicio teórico, utilizaremos algunos elementos salidos de nuestro trabajo de terreno para aclarar las afirmaciones que así lo requieran. Los resultados de la investigación serán publicados en detalle en otra oportunidad.

En la primera sección haremos una somera revisión de los tres modelos de militantismo típicos que surgen en el medio y comentaremos algunos de los problemas con los que se encuentran quienes intentan superarlos. En la segunda discutiremos cómo entender los procesos de subjetivación, uno de los elementos más utilizados en la explicación del compromiso militante y, sin embargo, más difíciles de operacionalizar. Finalmente, describiremos los ejes centrales de nuestra propuesta.

Subjetivación, estrategia y socialización en el campo de estudio del militantismo

Influidos por diversas escuelas, los cientistas sociales han construido diferentes imágenes del militante. A grosso modo, podemos resumirlas en dos tipos ideales: el militante de estructura y el militante estratega. Agregaremos a estos dos un tercero, el militante iluminado, más propio del imaginario de los militantes que de las ciencias sociales, pero aún así de gran importancia en el debate actual sobre la materia (para una categorización similar, ver Fillieule, 2001). 
El modelo del militante de estructura concibe el compromiso con una causa colectiva como el producto de creencias, de representaciones o de normas adquiridas por socialización. El pasaje al militantismo reflejaría, por ende, una conducta "natural" propia de la posición de los individuos en el espacio social. Como ejemplos de trabajos que se inclinan por esta imagen podemos mencionar la literatura de corte marxista que alude a la existencia de una suerte de sujeto universal en la clase obrera, aquellos estudios que surgieron de la escuela de collective behavior en los años setenta (ver Neveu, 2005), y más actuales, aquellas investigaciones que han buscado aplicar la teoría de Bourdieu a la materia ("Le capital militant", 2004). Todos estos enfoques tienen en común el hecho de otorgarle primacía a las condiciones estructurales de la acción por sobre otro tipo de elementos.

El modelo del militante estratega ha sido utilizado para deslegitimar la idea de que el compromiso militante representa una forma de sacrificio desinteresado por causas colectivas. Consiste en atribuir toda acción individual al producto de un cálculo racional entre costos y beneficios. El pasaje al acto dependería de las ventajas que éste podría acarrearle al interesado. La evolución del compromiso respondería, a su vez, a un cambio en dichas posibilidades. El trabajo de Marcur Olson estableció un precedente en materia de análisis de este tipo. Durante varias décadas especialistas de diferentes disciplinas han aplicado los principios del modelo de la acción racional. Podemos destacar como trabajos clásicos en esta línea el de Daniel Gaxie (1977) sobre el militantismo político, o el de Pierre Rosanvallon (1998) sobre la cuestión sindical donde dicho autor compara al militante sindical con un funcionario público.

El modelo del militante iluminado supone una suerte de personalización de las condiciones que hacen posible el compromiso militante. El individuo en cuestión poseería ciertas cualidades que lo hacen susceptible a la causa de otro. El compromiso militante aparece así como resultado de una "vocación". Si bien esta imagen aparece sobre todo en el relato de los propios militantes, tiende a permear muchas veces el discurso de los especialistas. De hecho, se hizo presente en varias de nuestras entrevistas a expertos en el tema sindical en América Latina. 
Decíamos que desde hace un tiempo existe un cierto consenso acerca de la necesidad de integrar estas distintas imágenes para comprender la realidad. Ni las condiciones sociales ni las acciones racionales pueden dar cuenta por sí solas del compromiso militante. Tampoco lo hace la idea de vocación. El primer modelo otorga un poder excesivo al medio sobre el actor, al punto que le es imposible explicar la diversidad de conductas que caracterizan al militantismo, así como a las sociedades contemporáneas (Becker, 1960; Dubet, 1994; Latour, 2007). El segundo modelo cae en la trampa contraria: atribuye un poder desmesurado al actor. Si bien en muchas ocasiones tendemos a actuar racionalmente, como lo muestran los relatos de vidas recogidos, esto está lejos de representar la regla general. Hay mucho que se escapa a la comprensión de los militantes. Asimismo, la capacidad para actuar racionalmente bajo ciertas circunstancias representa menos un elemento que puede explicarlo todo que un elemento a explicar, es decir, aquello cuyas condiciones deben ser explicitadas (Chazel, 1991; Dubet, 1994; Neveu, 2005; Tilly, 1991). Por poner un ejemplo sencillo, ciertas estrategias son posibles sólo en ciertas etapas del activismo sindical, y no en otras. El modelo de la vocación, por su parte, pierde de vista tanto la acción como el medio y reproduce la ilusión esencialista de la subjetivación. Ciertos individuos portarían en sí la capacidad de asumir una causa colectiva sin que sepamos qué es lo que los diferencia de otros y cómo es que dicha operación se hace posible (Bourdieu, 1986; Dubet, 1994; Wiviorka, 2008).

Desde los ochenta han surgido tentativas que van en el sentido de integrar las distintas imágenes disponibles sobre el militantismo. Una propuesta interesante por su nivel de sistematización es la de Fillieule, Péchu, Agrikoliansky y otros especialistas franceses que se han agrupado en torno a lo que han llamado "sociología del compromiso". Influidos por el interaccionismo simbólico, y sobre todo por el trabajo de Everett Hugues y Howard Becker, han definido el militantismo como una actividad social inscrita en el tiempo, caracterizada por la permanente relación entre una dimensión objetiva (cambios de posición, de responsabilidades, etc.) y una dimensión subjetiva (cambios en la perspectiva según la cual la persona percibe su existencia e interpreta la significación de lo que le afecta) 
(Péchu, 2001; Fillieule, 2001, 2005). Al mismo tiempo le otorgan una nueva significación al concepto de "retribución":

"Las razones del actuar [militante] mezclan siempre en grados evidentemente variables según el momento y la situación de la entrevista, móviles desinteresados que evocan retribuciones retiradas, retribuciones que tienen generalmente poco que ver con los cálculos de un hipotético actor racional. El encierro de la sociología del militantismo en las aporías de la oposición entre interés e ideología se explica sólo porque la sociología se ha mostrado sorda a la palabra de los actores" (Fillieule, 2005: 44).

En otras palabras, se intenta ampliar el concepto de retribución a formas de cálculo inconsciente y a cálculos sin fines materiales para, de esta manera, conservar su lugar en la explicación del militantismo, sin caer en los errores de la teoría de la acción racional clásica. El problema de esto radica, a nuestro juicio, en que la ampliación desdibuja los límites del concepto convirtiéndolo en una esponja que pretende abarcar todas las dimensiones sin distinguir ninguna, lo que lo hace peligrosamente incuestionable. Como bien plantea Chazel, los conceptos que abarcan mucho son finalmente imposibles de falsear (1991).

Siguiendo a Francois Dubet (1994), podemos identificar los aspectos puestos en relieve por los tres tipos ideales de militantismo como lógicas diferentes pero complementarias de la acción: la lógica de socialización, la lógica estratégica y la lógica de subjetivación. No es posible limitar la realidad a ninguna de ellas porque todas juegan un rol en el comportamiento militante. El rol del investigador consiste en sacarlas a la luz, diferenciarlas y establecer su interdependencia. Empero, la tarea no es en absoluto evidente. Primero porque, como insinúa Dubet, la relación entre éstas se halla siempre situada en el tiempo y el espacio. En consecuencia, sólo podemos identificarla a través del estudio empírico. Segundo, y es quizás el obstáculo mayor, no queda del todo claro qué debemos entender por subjetivación ni cómo distinguirla de los otros procesos. 
A menudo las investigaciones se contentan en afirmar o describir procesos de subjetivación sin explicitar los criterios que los definen. El concepto de subjetivación aparece generalmente ligado a la idea de resistencia a las determinaciones del medio (Dubet, 1994), es decir, a la capacidad de un individuo o grupo de experimentarse “(...) como actor, por la asociación de su libertad afirmada y de su experiencia vivida asumida y reinterpretada" (Touraine, 1996, citado en Wieviorka, 2008:20). Pero esta definición no explica verdaderamente lo que tendríamos que ser o hacer para que nuestro comportamiento merezca dicho título (Decombes, 2004).

\section{La lógica de la subjetivación}

No se ha zanjado si el sujeto constituye una propiedad antropológica y por ende inherente a todo actor o si se construye a lo largo de la experiencia. La mayor parte de las propuestas contemporáneas se inclina por integrar ambas concepciones. Esto constituiría una posibilidad humana intrínseca cuya realización o puesta en práctica dependería de ciertos procesos. El problema radicaría entonces en identificar esos detonadores. ¿De qué depende que un actor se subjetive? ¿Se trata de un proceso de "autosubjetivación" o de "heterosubjetivación"? Si cabe la posibilidad de ambos (Dumont, 1983; Wieviorka, 2008), ¿cómo resolver la contradicción inherente a la idea de una forma de autonomía impuesta por el medio?

Esta última pregunta adquiere una importancia especial en el debate contemporáneo. La individualización, proceso que ha sido impulsado por el Estado en las últimas décadas, exige al individuo convertirse en un ser más autónomo, es decir, un ser capaz de responsabilizarse de su trayectoria sin apelar demasiado a las instituciones públicas (Beck, U. \& Beck, E., 2003; Martucelli, 2002). ¿Representa entonces la individualización una forma de subjetivación? Cuesta aceptar esta idea, porque, en general, le atribuimos un efecto positivo a la subjetivación y negativo a la individualización, pero ¿cómo diferenciarlos? 
Para Michel Wieviorka el individuo representa:

"[...] una categoría más larga, que incluye el Sujeto, pero también el hecho o el deseo de participar en la vida moderna, el de consumir, el de acceder al dinero, al trabajo, a la educación [...] como persona singular $[\ldots]$ que no es la misma cosa que actuar" (Wieviorka, 2008:35).

Sin embargo, ¿̨por qué "el deseo de participar en la vida moderna" no puede resultar de un proceso de subjetivación? No basta con oponer integración a subjetivación, hay que explicar lo que las opone.

Un problema similar surge a la hora de distinguir la subjetivación de la estrategia. La individualización pareciera venir aparejada de un imperativo a actuar racionalmente. Hacerse cargo de su vida implica ponerse objetivos, planificar y crear estrategias adecuadas. Este ejercicio supone intentar ir más allá, desafiar las propias condiciones. En este sentido, ¿en qué se diferencia la acción estratégica de la idea corriente de subjetivación?

En resumen, si la idea de subjetivación busca dar cuenta de esos procesos por los cuales el actor es capaz de modificar sustantivamente su situación, debemos diferenciar esa forma de transformación de la que acarrea la acción estratégica o ciertas formas de socialización como la socialización individualista.

La propuesta de Alain Badieu es en este sentido iluminadora. Como otros, para Badieu la subjetivación representa un proceso fundamental en la historia humana, pues constituye el detonador de cambios sustantivos en todos los niveles de la vida social. Sin embargo, la subjetivación no tendría nada que ver con la idea de un ser autónomo o de un devenir autónomo, como lo planteaban los autores citados anteriormente. Para Badieu, el hecho de que el actor sea consciente de su libertad es irrelevante para el cambio social. La transformación viene de otro tipo de proceso: cuando un individuo o grupo es capaz de percibir la importancia de ciertos acontecimientos. En efecto, según Badieu, de cuando en vez surgen acontecimientos del todo impensados que entrañan en sí mismos un cuestionamiento a la "situación" o condiciones del mundo conocido. 
El acontecimiento abre una ventana hacia aquello que hasta ese minuto permanecía invisible o marginal. La subjetivación, por ende, representaría la capacidad de ciertos actores de identificar el potencial revolucionario que poseen esos eventos, "fidelizar" con ellos y hacerlos eficaces (Badieu, 1988).

Podemos decir que para Badieu la subjetivación presenta dos fases: una fase de reconocimiento (identifico en un evento aislado al acontecimiento) y una fase de actividad positiva o respuesta (nombro al acontecimiento, lo traduzco en una nueva "situación"). Según Slavoj Zizek, es aquí donde la propuesta de Badieu falla. Para Badieu, afirma Zizek, sólo existe un tipo de respuesta válida desde el punto de vista de los efectos que entraña en el orden, la del "maestro", es decir aquella donde se nombra el acontecimiento y se intenta producir un nuevo orden en referencia a lo que se percibe como nuevo. Sin embargo existen otras dos formas de respuestas que son subestimadas por Badieu: El "histérico" que cuestiona la nominación que el maestro hace del acontecimiento e insiste en la distancia que lo separa del orden desde donde surge y a donde quiere sometérsele; el "analista", quien defendiendo al igual que el histérico la irreductibilidad del acontecimiento a un orden simbólico, evita la trampa histérica y, en lugar de encontrarse atrapado en el círculo vicioso del fracaso permanente, afirma el carácter positivo y productivo de esta irreductibilidad, en otras palabras, la necesidad de que todo orden genere siempre un acontecimiento (Zizek, 2007).

¿Alguna de estas figuras supone un cambio social más significativo que el que entrañan las otras? Para Badieu se trata del maestro, para Zizek, del analista. Nosotros asumiremos una postura distinta. Independiente de cómo se manejen en una segunda instancia los nuevos elementos aportados por el acontecimiento, el solo hecho de haberlos reconocido, de haber identificado algo relevante en ese evento, genera un cambio fundamental en el mundo. El reconocimiento del acontecimiento crea lo que Rancière llama una "escena" pues vuelve evidente la precariedad de lo establecido y agrega incertidumbre respecto de la definición de ese mundo (Rancière, 1995). El litigio que dicha incertidumbre engendra puede resolverse a la manera del maestro, del histérico o del analista, sea como sea, produce un desplazamiento de las coordenadas del mundo. 
¿Cuál sería entonces el rol de la subjetivación en las trayectorias de vida y en qué se diferenciaría de la acción estratégica o de la socialización individualista? La subjetivación en tanto reconocimiento de un acontecimiento y su potencial revolucionario, representa el proceso detonador de los cambios significativos en la vida de un actor, es decir, aquel que modifica el mundo tal y como es habitado por él. Mientras que la individualización y la acción estratégica sólo pueden ser concebidas y generar cambios en un mundo de condiciones determinadas, la subjetivación es el mecanismo encargado de poner en cuestión una y otra vez esas condiciones.

Nos quedan dos puntos por aclarar. Primero, Badieu jamás habla de individuos o acontecimientos individuales. Su análisis se sitúa en un nivel macropolítico y su interés es entender los mecanismos que pueden generar cambios universales. Sin embargo, pareciera pertinente trasladarlo al plano individual. Las trayectorias de vida están marcadas por rupturas y cambios al igual que las trayectorias grupales. El individuo nace en un mundo dado y posee un horizonte limitado de posibilidades, sin embargo cada cierto tiempo ese mundo se transforma. Los conceptos utilizados por Badieu nos sirven para entender ese proceso. No obstante, quizás sea necesario distinguir teórica y empíricamente la subjetivación política de la que habla este filósofo político, donde lo que está en juego es el destino de una comunidad-Estado, de una subjetivación también política, pero cuyas consecuencias se limitan a la trayectoria de un individuo o de un grupo pequeño. Recordemos que la macro y la micropolítica no se diferencian sólo por su escala sino también por su naturaleza (Deleuze y Guattari, 1980). Invitamos a explorar en esta dirección.

El segundo punto a resolver es de carácter metodológico, ¿̨cómo el investigador puede identificar los acontecimientos que afectan la trayectoria de un actor diferente a sí mismo? Para Badieu existen en la historia un número limitado de verdaderos acontecimientos. La diferencia entre un acontecimiento y un hecho corriente radicaría en que el segundo no implica realmente una irrupción de algo nuevo que se escapa de la situación establecida. Pero, ¿quién evalúa entonces el carácter revolucionario del evento? Pareciera que Badieu da la primacía al observador externo; 
posición problemática puesto que éste no participa de las condiciones atacadas por el evento. Creemos en este sentido que el acontecimiento que vale es aquel que el propio actor identifica en un momento dado, de ahí nuestro interés por los relatos de vida de los trabajadores.

\section{El militantismo sindical}

A partir de estas reflexiones hemos definido la trayectoria de vida como una serie de "espacios" distribuidos en el tiempo, constituidos por un número limitado de combinaciones de estrategias posibles y de normas que pueden pesar eventualmente sobre la acción. Entre un espacio y otro encontramos diferentes acontecimientos cuya particularidad es justamente abrir un espacio a la vez en continuidad y en ruptura con el anterior. En continuidad, porque el acontecimiento que hace de bisagra tiene lugar en el espacio anterior. En ruptura, porque el nuevo espacio contiene una porción de nuevas estrategias posibles y pone en juego una serie de coacciones sociales antes inactivas o inexistentes. Asimismo, elimina otras posibilidades de estrategias antes vigentes y coacciones antes activas. El desplazamiento de un espacio a otro implica una reconfiguración de las condiciones de acción y, en este sentido, una redefinición del mundo que habita el actor.

Este modelo posee la ventaja de integrar las tres lógicas de acción que habíamos definido anteriormente, pero también de mostrar que las trayectorias no son lineales como muchas veces se afirma. La vida no representa un aumento o disminución progresiva de las oportunidades, ni tampoco la eterna repetición de las acciones que nos permiten las condiciones que hemos heredado al momento de nacer. Siempre existe un poco de las tres: creación, destrucción y repetición de oportunidades.

En el caso de las trayectorias militantes la tarea consiste en identificar dos fases de acontecimientos y espacios:

- Aquellos acontecimientos/espacios que crean las condiciones del compromiso inicial del individuo con una causa colectiva.

- Aquellos acontecimientos/espacios que van modificando de manera significativa dicho compromiso. 
¿En qué consiste entonces la trayectoria de un o una militante sindical? En términos generales, podemos plantear que el compromiso sindical supone la creación de un triángulo entre un individuo llamado a actuar en nombre de un grupo diferente a sí mismo, un grupo de trabajadores de base que busca ser defendido y una contraparte cuyos intereses se ven directamente afectados por cualquier acción que emprenda el primero en nombre de ese otro grupo de referencia. En otras palabras, está marcado por una relación particular del militante con un grupo de trabajadores de referencia (compañeros, trabajadores, clase obrera, etc.) así como por una suerte de oposición a una cierta figura que representa al capital (empleador, jefe, director, patrones, clase dominante, etc.).

Esta triangulación es inédita pues se forma en el minuto que un individuo asume una responsabilidad sindical. Ninguno de estos actores ni su interdependencia existían antes como tal al menos para el militante en cuestión. Ciertamente, en tanto que simple trabajador el potencial militante poseía vínculos con sus compañeros de trabajo, pero ese vínculo cambia de naturaleza cuando el individuo asume la función representativa: ya no es un simple individuo sino un individuo que significa a ese colectivo. Algo similar sucede con la figura de contraparte que aparece en el momento de la activación. A la relación de subordinación propia de la relación salarial se superpone una nueva relación, donde el militante exige del empleador un trato acorde con su nueva investidura. En este sentido, la activación sindical crea una nueva escena.

Sin embargo, la forma en que el militante representa estos dos actores y el tipo de relación que entabla con cada uno de ellos varían considerablemente en el tiempo. La escena no permanece intacta. De hecho, como pudimos verificar en los relatos de vida recogidos, hay momentos donde la fusión de identidades del militante con su grupo de referencia y la diferenciación con la figura del empleador se maximizan, adquiriendo ambos actores una consistencia de que carecerán en otros periodos. Hay momentos donde, por el contrario, la ilusión representativa se debilita y el militante tiende a diferenciarse de su comunidad de referencia, aun cuando continúa tratando de reivindicarla. En esos periodos la figura de la persona del militante tiende a adquirir un lugar más importante y se produce un 
cierto acercamiento a la figura de la contraparte. El militante llega incluso a asumir la representación de ciertos intereses de la empresa, pero nunca al punto de confundirse del todo con ella. En pocas palabras, la carrera del militante sindical está marcada por un constante juego de diferenciaciones y puestas en equivalencia respecto del grupo de trabajadores de referencia y la figura del capital.

En este sentido, para entender la trayectoria de los militantes sindicales debemos responder dos grandes preguntas:

- ¿Qué es lo que lleva a ciertos individuos a entrar/crear este triángulo del compromiso sindical? En otras palabras, ¿qué acontecimientos previos y, por lo tanto, qué espacios de estrategias y normas relevantes condicionan la creación de esta nueva escena?

- ¿Cómo dicho triángulo cambia de forma en el tiempo? ¿Qué acontecimientos y espacios van condicionando las nuevas formas de diferenciación y puestas en equivalencias del militante respecto de los otros dos actores?

Responder en detalle estas preguntas sobrepasa los objetivos de este artículo, sin embargo señalaremos algunos elementos que surgieron del análisis de los relatos de vida recolectados, de manera de mostrar la utilidad del enfoque que presentamos.

Debemos comenzar aclarando que, en el caso chileno, parecen existir diferencias significativas entre la generación de militantes que asume por primera vez una responsabilidad sindical antes o durante la dictadura militar de Pinochet, y aquella que lo hace luego de la transición en los años noventa.

Mencionaremos tres tipos de acontecimientos que parecen especialmente relevantes a la hora de entender la activación sindical de estas dos generaciones: acontecimientos/espacios asociativos, acontecimientos/ espacios profesionales y acontecimientos/espacios familiares.

La participación en otros espacios asociativos u organizaciones que defienden algún tipo de causa colectiva abre un espacio de oportunidades a la activación sindical. En general, supone la creación de redes sociales militantes que incluyen muchas veces representantes sindicales. La relación con una persona ligada al mundo sindical, su acción e influencia sobre el 
futuro militante, es fundamental en el paso al acto, sobre todo cuando se proviene de un medio familiar poco sindical. Esta relación funciona como dispositivo adelantado de socialización en los valores de este tipo de organización, pero también como detonador de nuevas necesidades estratégicas: la relación personal crea una suerte de dependencia donde el "otro" se transforma en un referente cuyo reconocimiento se demanda. El acontecimiento representado por la participación en otra forma de activismo abre un espacio de oportunidades también en otro sentido: implica un aprendizaje de valores militantes (la importancia del colectivo, de la solidaridad, etc.), y también de competencias necesarias para la gestión, organización y liderazgo. Estos valores y competencias empoderan al actor y lo hacen consciente de su capacidad para asumir desafíos de tipo colectivo, cuestión fundamental en el momento de la activación sindical.

La generación más antigua de militantes, los comprometidos antes o durante la dictadura, tienen, en general, activismos políticos o religiosos como antecedente. Su juventud transcurrió en una época de gran politización -entre la víspera de la Unidad Popular (UP) y la dictadura- donde la política permeaba casi todas las formas de asociatividad. La actividad sindical, la actividad religiosa, la actividad de partido, la asociatividad territorial, tendían a confundirse, tanto en términos de quienes participaban, los valores que se defendían, como de los objetivos que se planteaban: en la época de la UP la construcción de un orden político más justo; en la época de la dictadura el derrocamiento del régimen y la recuperación de la democracia. Por esto mismo, no era extraño participar en varias formas asociativas a la vez. La participación en una llevaba "naturalmente" a la otra. En otras palabras, los activismos representaban actividades complementarias. La represión durante los años de dictadura jugó un rol importante en este proceso de imbricación: la persecución los llevaba a buscar protección y asilo en instituciones religiosas donde se mezclaba actividad religiosa y sindical con la lucha por terminar con la dictadura.

La generación de militantes sindicales post dictadura también tiene como antecedente la participación en asociaciones que defienden causas colectivas, pero, en general, de tipo más "social" que "político". En efecto, la actividad política constituye más bien una excepción que 
la regla. Bomberos, asociaciones estudiantiles, scouts son, entre otras, las experiencias más comunes. Estas actividades no se complementan como en el pasado: se construyen en base a redes sociales diferentes y no comparten objetivos comunes. La lucha política dejó de ser el centro de gravitación y la bisagra de la actividad asociativa. De esta manera, el acontecimiento asociativo funciona en esta generación más como mediador de valores y competencias militantes que como creador de redes sindicales.

Lo que ocurre en la esfera profesional también afecta profundamente la trayectoria militante. El paso al acto pareciera estar estrechamente relacionado con cambios significativos en las condiciones de trabajo del potencial militante. Pudimos encontrar en los casos estudiados, tanto de la generación más vieja como en la más joven, dos tipos de acontecimiento opuestos: una desmejora o una mejora importante en la situación laboral personal del futuro militante. Ambos se miden en relación a experiencias pasadas o a las expectativas del momento. En el primer caso la actividad sindical aparece como única vía de reacción posible. Otras alternativas de solución del problema han sido descartadas: un empleador poco inclinado al diálogo con el trabajador, una oferta de empleos escasa o con condiciones laborales más precarias, etcétera. En el segundo caso la activación sindical viene de la mano de una disminución de su riesgo. La obtención de un contrato estable, el reconocimiento profesional del empleador, el aumento salarial, entre otros, otorgan una cierta seguridad al trabajador. Por un lado, la seguridad de que la actividad sindical no comprometerá en exceso su situación. Por otro lado, de que dadas las condiciones aventajadas en que se encuentra puede cumplir de mejor forma el rol de dirigente sindical. En ambos escenarios -desmejora o mejora notoria de las condiciones de trabajo- el potencial militante parte de la base de que no hay mucho que perder. En el primero pues no parecen existir otras alternativas, en el segundo porque las condiciones protegen al trabajador en cuestión.

La transformación de las condiciones de trabajo no favorece la activación sindical solamente por el hecho de que estratégicamente la vuelven conveniente, también porque detona un proceso de otra naturaleza: el reconocimiento del otro. En general, el cambio en la situación 
del trabajador parece venir acompañado de una toma de conciencia de la situación de quienes lo rodean y, por tanto, de la necesidad de hacer algo por ellos. La mejora, al aumentar la distancia que separa la situación personal de la del entorno, vuelve al futuro militante más susceptible a las injusticias ajenas, sobre todo cuando dada su experiencia familiar o asociativa previa ha sido socializado en valores como la igualdad, la solidaridad, etc. La distancia engendra, en este sentido, un conflicto de roles. En el otro caso, cuando las condiciones de trabajo del futuro militante se ven sensiblemente perjudicadas, el reconocimiento del otro viene de la mano de un proceso diferente. El futuro militante siente que no es reconocido ni por la sociedad ni por el empleador y esto, como plantea Honneth (2006), constituye un potente aliciente a la acción colectiva. El individuo en cuestión tiende a intensificar los vínculos con quienes comparte el sentimiento del desprecio. Sería interesante estudiar cómo y en qué medida estas dos vías distintas de reconocimiento del otro determinan formas diferentes de acción sindical. Dejamos por el momento la pregunta abierta.

El medio en el que el futuro militante nace y se desarrolla durante los primeros años de vida puede crear espacios a la activación sindical. En general, la generación más antigua viene de un medio politizado o sindical, aunque no siempre. Ello facilita su incorporación al mundo asociativo y, por ende, la cadena de acontecimientos que como hemos visto potencia el paso al acto. Esta condición se repite mucho menos en la generación post dictadura. La mayor parte no conoció ni la actividad sindical ni la política durante su juventud. El tipo de asociaciones en que participan da cuenta de ello. En estos casos la familia abre oportunidades a la activación sindical, porque transmite valores y competencias generales acordes con la acción colectiva, pero no como en la generación anterior, por una función de socialización más precisamente sindical.

Respecto de la evolución del compromiso sindical, mencionaremos un grupo de acontecimientos particularmente importante, los que están ligados a la formación.

En Chile los dirigentes asumen por primera vez responsabilidades sindicales sin mayor preparación, especialmente cuando están formando un sindicato. Potencia esta situación la falta de una política de acompañamiento 
y formación sistemática por parte de las estructuras sindicales mayores como las federaciones, confederaciones y centrales. Quizás en parte es por esta razón que muchos de los sindicatos que se forman no se afilian a este tipo de estructura. En general, acuden a ellas por ayuda en algún momento, pero frente a la escasa atención que se les concede, tienden a abandonar la iniciativa. La falta de preparación suele volver difícil los primeros años de actividad sindical más aún, por cuanto en la generación más antigua una buena parte de ellos posee un bajo nivel educacional, y en la generación más joven, carecen de experiencia política.

Para llenar el vacío de asesoramiento por parte de otras estructuras sindicales, los dirigentes acuden a otro tipo de instancias. La Inspección del Trabajo es una de ellas. Sorprende cómo el Estado, a través de esta institución, cumple con un rol fundamental en los primeros años de la militancia sindical: otorga información y protección al militante, pero también constituye un medio común de presión sobre los empleadores durante esta etapa. La acción de la Inspección del Trabajo sobre la forma del compromiso militante puede resumirse en dos. En primer lugar, como agente moderador de la oposición que se crea con el grupo representante del capital en tanto que favorece el diálogo por sobre el enfrentamiento. En segundo lugar, como agente potenciador de la función representativa del militante y, por tanto, de la consolidación de la colectividad salarial en cuestión. De hecho, al entregarle protección e información, insta al militante a asumir la responsabilidad pese a los riesgos aparejados. En la medida en que se transforma en herramienta de presión, a menudo exitosa, durante los primeros conflictos entre el militante y la oposición, exalta la identificación del colectivo al militante y empuja un cambio en la actitud de los empleadores respecto de este último.

Pero uno de los acontecimientos más significativos relacionados con la formación en términos de crear una ruptura en la escena sindical es el acceso de los militantes a carreras universitarias o escuelas sindicales impartidas por universidades privadas o públicas. En parte, porque buscan cumplir mejor sus funciones sindicales, en parte porque el estatus de dirigente los ha empoderado, ha despertado nuevas ambiciones; además de concederles oportunidades únicas en términos de seguridad laboral y 
flexibilidad horaria, los militantes sindicales tienden a buscar completar su formación sindical o profesional en universidades. La adquisición de nuevas competencias tiende a diferenciar al dirigente de los trabajadores que representa. Se crea un espacio donde el conflicto entre el militante y el colectivo de referencia respecto de las estrategias a utilizar y la evaluación de las situaciones se hace más frecuente. La importancia que el militante le concede en su discurso a sus características personales tiende a acentuarse. Esta separación se radicaliza en el caso de quienes completan sus estudios profesionales. En general, se trata de programas en el dominio de la gestión o administración de empresas, lo que sin duda representa una paradoja. De hecho, este acontecimiento le otorga mayores oportunidades profesionales y crea mayores expectativas en el militante. Por otro lado, como bien destacaron los mismos dirigentes entrevistados, los socializa en un ambiente profundamente antisindical. Como resultado, sobre todo en la generación más joven, muchos terminan optando por la carrera profesional en detrimento de la carrera sindical.

Como ejemplo, hemos subrayado algunos de los acontecimientos que van haciendo posible el compromiso sindical y modificándolo a través del tiempo. Lo fundamental es no perder de vista que cada uno de ellos no determina por sí solo esos procesos. Cada acontecimiento representa un eslabón que abre un espacio donde el acontecimiento siguiente se vuelve probable. Lo que importa, particularmente, es todo su encadenamiento.

A modo de conclusión, queremos reiterar las dos ventajas más importantes del modelo de interpretación que hemos propuesto. En primer lugar, permite observar la dinámica del compromiso sindical poniendo el acento tanto en las continuidades como en las discontinuidades. El militantismo sindical se ha modificado a lo largo de las últimas décadas, pero también se modifica al interior de la vida de un individuo. Estas transformaciones no son lineales ni simples como algunas tesis plantean: crisis y fortalecimiento del compromiso sindical son dos caras que se alternan en el tiempo. Finalmente, integra al análisis diferentes lógicas de acción, sin darle prioridad a una sobre la otra. El compromiso sindical no se explica ni exclusivamente por la acción estratégica ni exclusivamente por la socialización de los militantes. Ambas intervienen en el proceso. 


\section{Referencias}

Agrikoliansky, E. (1980). Carrières militantes et vocation à la morale: les militants de la LDH dans les années. Revue française de science politique, 51, 27-46.

Badieu, A. (1988). L'Être et l'Événement. París, Francia: Seuil.

Beck, U. \& Beck, E. (2003). La individualización. El individualismo institucionalizado y sus consecuencias sociales y politicas (B. Moreno, Trad.). Barcelona, España: Paidós. (Trabajo original publicado en 2002).

Becker, H. (1960). Notes on the Concept of Commitment. The American Journal of Sociology, 66(1), 32-40.

Chazel, F. (1991). Action collective et mobilisation individuelle. En P, Birnbaum \& J. Leca (Eds.). Sur l'individualisme, pp.244-268. París, Francia: Presses De Sciences Po.

Decombes, V. (2004). Le complément du Sujet. París, Francia: Gallimard.

Deleuze, G. y Guattari, F. (1980). Capitalisme et schizophrénie 2. Mille Plateaux. París, Francia: Les Éditions de Minuit.

Dubet, F. (1994). Sociologie de l'expérience. París, Francia: Seuil.

Dumont, L. (1983). Essaie sur l'individualisme. París, France: Seuil.

Foucault, M. (1984). Histoire de la sexualité. Volume III. Le souci de soi. París, Francia: Gallimard.

Fillieule, O. (2005). Temps biographique, temps social et variabilité des rétributions. En O. Fillieule (Ed.). Le désengagement militant, pp.1748. París, Francia: Belin.

Fillieule, O. (2001) Propositions pour une analyse processuelle de l'engagement individuel. Post scriptum. Revue française de science politique, 51, 199-215.

Gaxie, D. (1977). Economie des partis et retribution du militantisme. Revue Francaise de science politique, 27(1), 123-154.

Honneth, A. (2006). La Société du mépris. París, Francia: La Découverte.

Latour, B. (2007). Changer de société. Refaire la sociologie. 2a ed. París, Francia: La Découvert. Le capital militant. Engagements improbables, apprentissages et techniques de lutte. (2004). Actes de la recherche en sciences sociales, 155(4).

Martuccelli, D. (2002). Grammaires de l'individu. París, Francia: Gallimard. McAdam, D., McCarthy, J. \& Zald, M. N. (1996). Comparative Perspectives on Social Movements. Cambridge, UK: Cambridge University Press.

Neveu, É. (2005). Sociologie des mouvements sociaux. 4ta ed. París, Francia: La Découverte. 
Nicourd, S. (dir) (2009). Le travail militant. Rennes, Francia: Presses Universitaires de Rennes.

Olson, M. (1978). Logique de l'action collective. 3era ed. París, Francia: PUF.

Péchu, C. (2001). Les générations militantes à droit au logement. Revue française de science politique, 51, 73-103.

Rancière, J. (1995). La Mésentente. Politique et philosophie. París, Francia: Galilée.

Rosanvallon, P. (1998). La question syndicale (2a Ed). París, Francia: Hachette Litteratures.

Tilly, C. (1991). Action collective et mobilisation individuelle. En P. Birnbaum \& J. Leca (Eds.). Sur l'individualisme, pp.213-243. París, Fondation Nationale des Sciences Politiques.

Touraine, A. (1996). Qu'est-ce que la Democratie? París, Francia: Fayard.

Wieviorka, M. (2008). Neuf leçons de sociologie. París, Francia: Robert Laffont.

Zizek, S. (2007). Le Sujet qui fache. París, Francia: Flammarion.

Fecha de recepción: 01 de abril de 2010.

Fecha de aceptación: 08 de julio de 2010. 